\title{
Examples of Applying Research-Based Learning Principles to the Redesign of an Environmental Geotechnics Course
}

\author{
https://doi.org/10.3991/ijep.v10i1.11181 \\ Marina Pantazidou ( $\square)$ \\ National Technical University of Athens, Zografou, Greece \\ mpanta@central.ntua.gr \\ Kyriakos Kandris \\ Emvis Consultant Engineers SA, Ag. Paraskevi, Greece
}

\begin{abstract}
This paper offers detailed examples of how research-based learning principles can be translated into the instructional decisions involved in designing an engineering course. The redesign of the specific course on environmental geotechnics was prompted by transforming a lecture-based course to an online version. The implemented changes are compatible with research findings on learning, which are distilled in the literature in the form of the learning principles reviewed herein. For presentation purposes, the changes are grouped in two main categories: logistical changes, i.e. modifications mainly imposed by the constraints of online study, and pedagogical changes, i.e. changes not related to the learning medium. Examples of implemented modifications are given in the body of the paper and in an online Supplement. In most cases, the initial motivation for a change was not to achieve compatibility with results of research on learning. Rather, the intended overarching aim was to make transparent the major decisions involved in course design. As far as the paper is concerned, its ultimate goal is to engage engineering instructors in contributing to communal teaching resources. Its immediate goal is to make explicit the relationship between good instructional practices and the research evidence that supports them through a variety of examples. In the process of so doing, the paper identified the research need to record how domain experts understand foundational domain concepts in a way suitable for use in instruction.
\end{abstract}

Keywords - Course design, civil engineering, evidence-based practice, case study, tacit expert knowledge.

\section{Introduction}

This paper belongs in the genre "Case Study of Designing an Upper-Level University Course" and describes elements of the redesign of an elective course on Environmental Geotechnics. Course design includes

- The methodology of selecting the building components of a course. 
- Decisions concerning the main desired outcomes of the course, respective assessment methods (for diagnostic and evaluation purposes) and materials (assignments, projects, mid-term and final exam questions).

- The development of necessary teaching materials. The object of Environmental Geotechnics is the protection of the subsurface (soil and groundwater) from potential pollutants related primarily to waste management (e.g. landfills) and to transporting, storing and handling toxic raw materials (e.g. petroleum products, solvents).

The course has been taught for several years in the $9^{\text {th }}$ semester of the 5-year integrated civil engineering curriculum at the National Technical University of Athens (NTUA), Greece (see online [1]). The first author of the paper is the course instructor and the second author was the graduate student teaching assistant. The redesign was prompted by the NTUA-wide project for the creation of open online courses, which funded the creation of a platform and the presentation of existing educational materials in a consistent format. The online version of the environmental geotechnics course is in Greek and it is meant for self-paced study (see online [2]).

The environmental geotechnics course has been evolving through the years [3], [4], [5] within the framework of scholarship of teaching [6]. For the course version described herein, combining existing and new material lessened the burden compared to creating everything from scratch and freed time to address structural issues. The single most important aim for this version is to make course design decisions transparent to students and colleagues. A second goal emerged from the separation of the live version of the course from its static online counterpart, as an opportunity to bring to the fore the essence and the logic of the subject taught. Absent online instructors have to be more organized and more attentive to their imagined students; hence, the online version required targeted changes, which ended up benefitting the live version of the course as well.

The paper is written with the intention to highlight the research evidence underpinning the practices followed. Good pedagogy typically originates from two sources: the intuition of the instructors, drawn from their experiences as students and teachers [7], and instructional strategies grounded in research results from the science of learning [8]. Although the two sources of inspiration may often converge to similar results, it is unlikely that every required instructional intervention will originate from experience alone. Hence, familiarity of instructors with the literature on education is highly recommended, as there is evidence of positive correlation with their students' achievement level [9].

Within this context, this paper uses the opportunity of the redesign of the environmental geotechnics course to give examples of

- The guidance instructors can find in research on learning

- How can they readily apply this guidance to their courses?

To this end, the paper starts with introducing the main principles that underpin practices implemented during redesign (Section 2), as they are presented by Ambrose et al. in "How learning works: 7 research-based principles for smart teaching" [8]. In 
order for these good practices to reinforce each other, it is best to be implemented within a systematic course design framework. Because of its foundational role, the selected course design framework "Understanding by Design" by Wiggins and McTighe [10] is discussed in a separate section (Section 3.1), together with examples of its application. The paper then describes modifications made, starting from the changes necessitated primarily by the online format (Section 3.2), which are referred to as logistical because initially they were driven by ease-of-use. Finally, the paper gives examples of pedagogical changes (Section 3.3), which are unrelated to the online medium. For presentation convenience, pedagogical changes are further subdivided into methodology-driven changes (how to teach) and content-related changes (what to teach). Major course decisions and implemented changes are accompanied with specific representative examples throughout the paper. For the use of interested readers, additional examples are provided in a Supplement, together with PowerPoint presentations (translated in English), available on the first author's webpage (see online [11]).

\section{$2 \quad$ Learning Principles and Associated Teaching Practices}

Ambrose et al. [8] write for the instructors who want the gist of research on education and the implications of this research translated into readily-applied good teaching practices. They focus on seven learning principles, identify the main implications of these principles expressed as goals, i.e. teaching approaches meant to support desired student activities and attitudes, and offer a large variety of teaching strategies to achieve these goals. This paper extends their work by

- Proposing specific domain-general practices of implementing these strategies

- Providing, for each proposed practice, a concrete example from the previously described environmental geotechnics course.

Tables 1 and 2 list five of the seven principles, which underpin changes implemented in the course and reported herein. For ease of reference throughout the paper, each principle is assigned a number and a short name: 1-prior knowledge, 2knowledge organization, 3-mastery (see Table 1), 4-motivation and 5communication (see Table 2). Under each principle, Tables 1 and 2 show the implication of each principle expressed as major goals and the subset of associated strategies from [8] that were salient to the design of the environmental geotechnics course. For each principle, Tables 1 and 2 provide several domain-general instructional practices to turn strategies into actions. They also reference the indicative examples of implemented strategies in the environmental geotechnics course that are discussed in the paper and the additional examples included in the Supplement. Table S1 of the Supplement (in online [11]) is an expanded version of Tables 1 and 2, and describes examples for every implemented strategy. The corresponding teaching materials (translated in English) are provided as Exhibits S1 through S20. Learning principles and associated goals and strategies are introduced in this section, while their specific con- 
nection to the design of the environmental geotechnics course is described in Section 3.

Table 1. Learning principles 1 to 3 : Suggested practices for the implemention $\uparrow$ of strategies recommended by Ambrose et al. [8] and correspondence to examples-exhibits S1 to S20 in the online Supplement [11].

\begin{tabular}{|l|}
\hline \multicolumn{1}{|c|}{ 1. Prior Knowledge Principle } \\
\hline $\begin{array}{l}\text { Goal: Activate prior knowledge, Strategy: Link material among courses and within the course (trigger } \\
\text { recall) }\end{array}$ \\
\hline - Enrich each lecture with diagnostic quiz-type questions ${ }^{\text {a }(\mathrm{S} 1)}$ \\
\hline - Create material to highlight links among civil engineering courses (S2) \\
\hline $\begin{array}{l}\text { Goal: Identify and address prior inaccurate knowledge, Strategy: Ask students to justify their reasoning } \\
\text { (uncover prior beliefs) }\end{array}$ \\
\hline - Elaborate beliefs about prerequisite concepts - devise interventions ${ }^{\text {b }}$ (S3) \\
\hline - Uncover beliefs about key concepts - devise interventions (S4) \\
\hline \multicolumn{1}{|c|}{ 2. Knowledge Organization Principle } \\
\hline lectures, course
\end{tabular}

${ }^{\dagger}$ The examples of strategy implementation discussed in the text are shown with superscripts ${ }^{a}$ to ${ }^{\mathrm{d}}$. More examples and educational material are available in online [11].

"An example of a quiz-type question from "Unit 4: Subsurface flow" is given in Figure 2. Quiz-type questions from all course units are available in the Supplement.

${ }^{\mathrm{b}}$ Beliefs about pollutant molecules \& background on the ground coffee - instant coffee analogy. Presentation slides are available in online [11].

${ }^{c}$ The relationship between essential questions and course units is shown in Table 3.

${ }^{\mathrm{d}}$ Figure 1 demonstrates the contribution of each mechanism (retardation, degradation, dispersion) to contaminant transport. Additional material is included in online [11].

\subsection{Prior knowledge principle: "Students' prior knowledge can help or hinder learning"}

When students connect what they are learning to relevant prior knowledge from another or the same course, they learn and retain more. In addition, there is evidence that when recall is triggered (e.g. with the aid of quiz-type questions), the process of retrieval itself contributes to further learning [12]. However, if prior knowledge is inaccurate and remains undetected, it will hinder learning. Hence, the goal for the instructor is to first identify the inaccurate knowledge and then develop educational 
material to address it. Ambrose et al. [8] appear to assume that inaccurate prior knowledge is always apparent to instructors. But this is not so, at least in engineering, where knowledge builds on prerequisite understandings, often from other disciplines. For example, students may hold inaccurate prior knowledge from physics or chemistry, e.g. [13], as discussed in an example in the section "Content-related changes".

\subsection{Knowledge organization principle: "How students organize knowledge influences how they learn and apply what they know"}

Instructors may assume that because they organize their courses in a certain way, this organization structure will be apparent to their students, or that students will be able to create their own structure. But, for students this is the exception, rather than the rule, since a highly organized structure of specific knowledge in a domain is a characteristic attribute of expert performance [14]. Ambrose et al. [8] too stress that the density of connections among concepts, facts and skills characterizes experts' knowledge organization. Students can use all the help instructors can give them to arrange what they learn. An often neglected component of the organization of knowledge is its usefulness (why do students have to learn something). Instructors can help students develop knowledge organization skills by making explicit the organization structures at every level: curriculum, course, and lecture.

\subsection{Mastery principle: "To develop mastery, students must acquire component skills, practice integrating them, and know when to apply what they have learned"}

This principle is partly linked to the previous, since it deals with assisting students with progressing along the novice-expert continuum. To this end, instructors should break complex tasks to their components and provide students with opportunities to practice component tasks. But, when experts attempt to identify component tasks, their own efficient performance becomes an obstacle to identifying steps and rules, aptly referred to in the literature as the "expert blind spot" [8], [10]. Hence, during fine-tuning of educational material, it is useful for the instructor to collaborate with a teaching assistant who can offer a perspective from an in-between expertise level. To avoid having the practice of component tasks result in rote learning (e.g. student memorizing solutions of standard problems), instructors should also design opportunities for students to practice integration. This can be achieved by scaffolding complex task performance in a variety of ways, such as reducing the cognitive load of the complex task, supporting some aspects of the complex task, and providing rubrics specifying grading criteria.

\subsection{Motivation principle: "Students' motivation determines, directs, and sustains what they do to learn"}

This principle and the next focus more on the psychological-behavioral aspects of learning, which support the cognitive. Ambrose et al. [8] give a thorough overview of 
the motivational aspects of learning by first defining motivation as personal investment affected by

- The subjective value of a goal

- The expectations of its successful attainment, or expectancies.

Although instructors have little say in the goals students set for themselves, they can exert some indirect influence. Ambrose et al. [8] offer a variety of strategies for instructors to establish values (which in turn can affect goals) and to build positive expectancies. Concerning the subjective value of the tasks, instructors can make material interesting by assigning authentic, real-world tasks, to the extent allowed by the subject matter. And, irrespective of the subject matter, instructors can make a significant difference by helping students hold positive expectancies by implementing strategies such as: clearly describing expectations, giving diagnostic tests to gauge class level and create assignments at appropriate level, and offering grading rubrics to show students what is important. It helps if the above practices are placed within a consistent course design framework to ensure that objectives, assessment and instructional practices align (see Section 3.1).

Table 2. Learning principles 4 and 5: Suggested practices for the implemention ${ }^{\dagger}$ of strategies recommended by Ambrose et al. [8] and correspondence to examples-exhibits S1 to S20 in the online Supplement [11].

\begin{tabular}{|l|}
\hline \multicolumn{1}{|c|}{ 4. Motivation Principle } \\
\hline Goal: Increase subjective value of learning goal, Strategy: Assign authentic, real-world tasks \\
\hline - Create a case study for each course unit ${ }^{\mathrm{e}}$ (S13) \\
\hline - Create realistic assignments (S14), mid-term (S15) and final exam questions (S16) \\
\hline $\begin{array}{l}\text { Goal: Hold expectation for successful attainment of goal, Strategies: Align objectives-assessment- } \\
\text { instructional practices, Articulate expectations, Use rubrics }\end{array}$ \\
\hline - Use Understanding by Design framework [10 ${ }^{\text {f }}$ (S17) \\
\hline - Highlight connections between learning outcomes and assigned work ${ }^{\mathrm{g}}$ (S18) \\
\hline \multicolumn{1}{c|}{ 5. Communication Principle } \\
\hline Goal: Practice towards specific goals, Strategies: Be specific about goals, State learning outcomes \\
\hline - Communicate essential questions in course introduction (S5) \\
\hline - Provide detailed learning outcomes for each course unit ${ }^{\text {h }}$ (S19) \\
\hline - Highlight connections between learning outcomes and assigned work ${ }^{\mathrm{g}}$ (S18) \\
\hline Goal: Provide feedback, Strategy: Provide feedback at the group level \\
\hline - Discuss in class answers to quiz questions (S20) \\
\hline
\end{tabular}

$\dagger$ The examples of strategy implementation in the environmental geotechnics course discussed in the text are indicated with superscripts ${ }^{\mathrm{e}}$ to ${ }^{\mathrm{h}}$. Additional examples and related educational material are available in online [11].

"Case study "Graces Quarters" for "Unit 2: Risk assessment", the PowerPoint presentation is available in [11].

${ }^{\mathrm{f}}$ The framework by Wiggins and McTighe [10] is discussed in Section 3.1.

g Examples of connections between assigned work and learning outcomes for "Unit 7: Contaminant transport in groundwater" are given in Table 4.

h Detailed learning outcomes for "Unit 7: Contaminant transport in groundwater" are given in Table 3 and for "Unit 4: Subsurface flow" and "Unit 6: Soil-contaminant interaction" in online [11]. 


\subsection{Communication principle: "Goal-directed practice coupled with targeted feedback enhances the quality of students' learning”}

The basis for this principle is communication (of both goals and feedback), hence its short name. Most instructors, in their minds, have clear ideas on performance goals for their students. In order for these performance goals to be the drivers of the course, they need to be clearly stated in writing as learning outcomes and communicated to students. Learning outcomes provide a more accurate picture of the identity of the course, compared to course contents, not only to students, but also to colleagues and program assessors. Learning outcomes not only direct focused practice (and, hence, link this principle to the mastery and motivation principles), but also are the basis for evaluation and shape targeted feedback, provided either at the individual or at the group level.

\subsection{Comments on learning principles}

The selection and the ordering of the five learning principles were made with the following rationale. Principles 1 to 3 are connected closely to the subject matter and, hence, may appeal more to instructors favoring teacher-based models of instruction that, traditionally, focus on content. Principles 4 and 5 stress more the personal experience of the learner, i.e. they are more compatible with learner-based models of instruction, whereby instructors encourage students to take charge of the learning process. However, although the main emphasis may differ, both sets of principles aim to create learning environments in which students perform better.

As indicated, pairs of principles (e.g. knowledge organization-mastery principles, motivation-communication principles) have close connections and even partial overlaps. Accordingly, some strategies stem from more than one principles, hence it is possible that their implementation may have a more powerful effect on student learning.

The remaining two learning principles are described in [8] with the following statements. "Students' current level of development interacts with the social, emotional, and intellectual climate of the course to impact learning" and "To become selfdirected learners, students must learn to assess the demands of the task, evaluate their own knowledge and skills, plan their approach, monitor their progress, and adjust their strategies as needed." These two principles are mentioned for completeness but not discussed further herein because they are not relevant to static online courses, as the first concerns and the second requires interactions among students and instructors.

\section{Course Redesign}

\subsection{Course design framework: major organization tool}

A course design framework, or instructional framework, consists of a collection of general rules or steps that guide the decisions of an instructor planning a lecture or a 
course, or designing interventions and instructional materials. Herein the instructional framework "Understanding by Design" by Wiggins and McTighe [10] was selected, mainly because its starting point is closely tied to the core of the subject matter, as will be explained below. Another incentive for using this framework is that the engineering education literature offers examples of its use for designing an online course [15] and for independent evaluation of the design of several courses [16].

The Understanding by Design framework consists of three stages:

- Identifying the desired results or goals

- Determining the acceptable assessment evidence

- Planning the learning experiences and instruction, in that order.

Its name stems from its backward nature. Instructors first state the goals and desired results (what do I want the students to be able to do?), which, in the education literature, are referred to as learning outcomes. They then stipulate the necessary evidence that the goal has indeed been achieved: this step describes the types of tasks students should be able to complete. Lastly, instructors create the teaching plan and the instructional materials that will enable the students to complete these tasks and perform according to the stated goals. The backward design ensures that objectives, assessment and instructional practices align (4-motivation principle).

This particular design framework recommends that instructors begin by organizing units of instruction around the "Big Ideas" the course aims to develop (2-knowledge organization principle, 5-communication principle). According to Wiggins and McTighe [10], "a big idea is a concept, theme or issue that gives meaning to discrete facts and skills". Big ideas are not chapter headings in textbooks. Big ideas are closer to the organizing principles used by experts in arranging domain knowledge. Or, again in the words of Wiggins and McTighe [10], "they are the hard won results of inquiry, ways of thinking and perceiving that are the province of the expert".

Herein the big ideas are introduced with the help of "Essential Questions" that, according to Wiggins and McTighe [10], "point to and highlight the big ideas" and "push us to the heart of things - the essence". The environmental geotechnics course is built around four essential questions that convey the big ideas (3-mastery principle), and also offer the opportunity to wrap up the course by formulating the respective answers.

Table 3 lists the essential questions and shows their relationship to the ten units of the course. Four units [Units 3-4 and 6-7] cover the engineering fundamentals of the course. Instruction in the environmental geotechnics course begins with establishing the applied context with the help of case studies, and explaining that the case studies guide the choice of the essential questions (Unit 1). Students know from Day 1 that the four essential questions motivate the selection of course content (Units 2 through 10). These questions allow the more independent students to gradually formulate their own answers throughout the course and can help all students appreciate their answers, when discussed at the end of the course. Essential questions are phrased in everyday language, without technical terms. When they are revisited at the course's completion, technical terms are used, as appropriate, in discussing the answers (see example in footnote of Table 3 - all answers are included in online [11], Exhibit S12). 
Table 3. Essential questions and related units of the course on environmental geotechnics.

\begin{tabular}{|c|c|}
\hline Essential Questions & Related Course Units \\
\hline & $\begin{array}{l}\text { Unit 1. Setting the stage - Introduction: case studies of } \\
\text { contaminated sites, introduction of essential questions, } \\
\text { legislation, sources and characteristics of contaminants) }\end{array}$ \\
\hline What is the danger (from pollutants)? & Unit 2. Risk Assessment \\
\hline \multirow{5}{*}{ Where will the pollutant go, how will it behave? } & $\begin{array}{l}\text { Unit 3. Mechanisms of pollution spreading (qualitative } \\
\text { description) }\end{array}$ \\
\hline & Unit 4. Subsurface flow \\
\hline & Unit 5. Modeling of physical systems \\
\hline & Unit 6. Soil-contaminant interaction \\
\hline & $\begin{array}{l}\text { Unit 7. Contaminant transport in groundwater (quantita- } \\
\text { tive-mathematical description) }\end{array}$ \\
\hline \multirow{2}{*}{ What can we do to reduce the danger? } & Unit 8. Remediation technologies for contaminated sites \\
\hline & Unit 9. Landfill liner design and materials \\
\hline $\begin{array}{l}\text { When are things }{ }^{\dagger} \text { relatively easy or difficult and } \\
\text { why? }\end{array}$ & $\begin{array}{l}\text { Unit 10. Wrapping up: answering }{ }^{\ddagger} \text { essential questions } \\
\text { (Synthesis from prior units) }\end{array}$ \\
\hline
\end{tabular}

† By "things" we mean "contaminated sites".

* Answer to this last question is built gradually in different units and discussed upon completion of the course: "We can differentiate among difficult cases of pollutant release (long-term releases, large quantities), difficult pollutants (persistent pollutants, non-aqueous phase liquids) and difficult sites (heterogeneous soil, low-permeability soil and combinations with difficult releases and difficult pollutants)." Answers to all questions are provided in online [11] (Exhibit S12).

It is impossible to overstress the importance of essential questions and at the same time it is difficult to explain their necessity. It is difficult because essential questions are like the load-bearing frame that holds a building together while it remains unseen. The four essential questions in Table 3 are the reinforced-concrete frame of the course -everything else in the course corresponds to all the remaining components of the building combined. However, unlike the load-bearing frame of a building, which is constructed first, essential questions and big ideas mature gradually in the minds of instructors and often belong in the realm of tacit expert knowledge. Writing them down is not an easy undertaking, like most things we come to take for granted: for the first author, it took nearly 25 years of teaching the course and familiarity with engineering practice in the field of environmental geotechnics and required the compelling arguments of Wiggins and McTighe [10] for the necessity of phrasing them. It is no wonder, then, why essential questions and big ideas are rarely committed to writing and, hence, remain hidden from students (and colleagues).

Once course units are formulated around essential questions, detailed outcomes are stated for each unit so that these too be shared with students. Table 4 lists as examples Outcomes 1 through 5 for Unit 7, Contaminant transport in groundwater (Exhibit S19 lists outcomes for Units 4 and 6 as well). Each outcome is followed by the respective assessment activities (in parentheses), which dictate the needed teaching materials. In Table 4, outcomes are followed by descriptions in brackets when the achievement of the stated outcome required creating additional educational material and/or tailoring accordingly the teaching plan. For example, in achieving Outcome 1 students are supported with a graphic developed with this outcome in mind, as shown in Figure 1. 


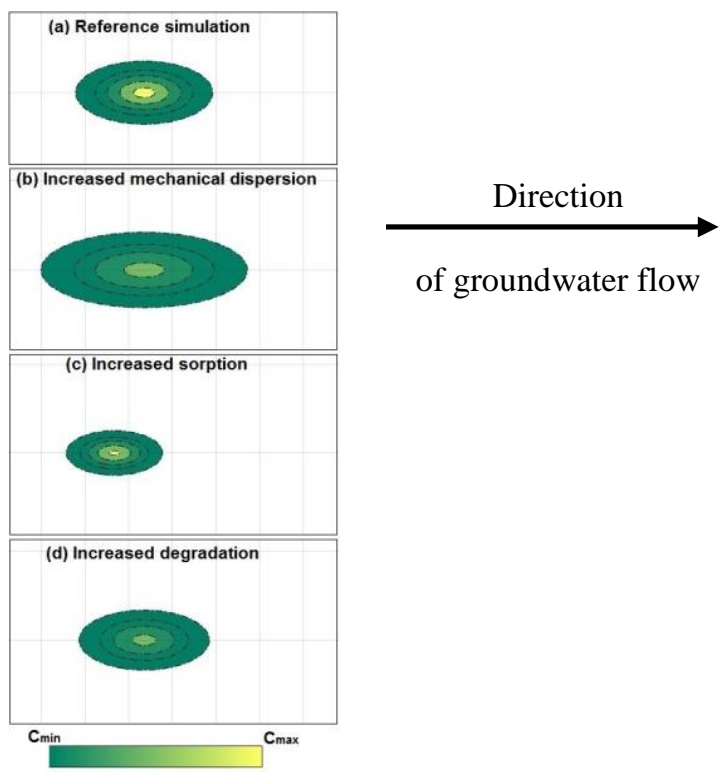

Fig. 1. (a) Contaminant plume due to instantaneous release from point source and illustration of the effect of increased (b) mechanical dispersion, (c) sorption and (d) degradation. $\mathrm{Cmax}=1500 \mathrm{Cmin}$. Additional background material is included in online [11].

In addition, students get in-class instruction on the use of an educational interactive software for contaminant transport [17], which they subsequently use for homework assignments and the term project. Likewise, Outcome 5 necessitated explicit instruction in modeling of physical systems, as described in [3].

Table 4. Learning outcomes of Unit 7 Contaminant transport in groundwatert, types of assessment (in parentheses) and required additional teaching material \{in brackets\}.

1. I can estimate the relative contribution of transport phenomena for specific combinations of pollutants, soils and characteristics of the flow and transport fields (term project) \{new graphic: Figure 1 and use of educational software [17]

2. I am familiar with searching in the literature for values of transport parameters (homework assignments) 3. I can back reasonable estimates for the values of the parameters involved in a problem of contaminant transport (term project)

4. I am aware of a variety of analytical solutions of the equation for contaminant transport and I understand the limitations of each one (homework assignment and final exam)

5. I can select from a variety of analytical solutions of the transport equation the one that fits better the geometry of a contaminant release and the expected contribution of the transport phenomena (term project) \{explicit instruction in modeling of physical systems [3]

$\dagger$ The Supplement in online [11] includes learning outcomes of Unit 4 Subsurface flow and Unit 6 Soilcontaminant interaction (Exhibit S19). 


\subsection{Logistical changes: Making online material more user-friendly}

To make up for the absence of a teacher who can clarify things, two priorities were set for the online course: reducing the cognitive load for the online user and outlining explicitly the connections between course topics and supporting material. This section discusses the main changes made to the presentation of the course material in its online version.

Cognitive load was reduced by a variety of modifications, such as:

- In anticipation of a future online version with videotaped presentations, existing presentations were broken in smaller subunits. For example, the core units of the course on groundwater flow, soil-contaminant interaction and contaminant transport broke in four presentations each, from the initial two, one, and two presentations, respectively.

- A lot of thought went into assigning a meaningful title to each subunit (see Exhibit S6 in online [11]). (The first author was surprised to realize with embarrassment that some existing presentations were missing a proper title.)

- Each subunit ends with highlighting the main points or the main desired understandings (see Exhibit S10), and each unit ends with detailed learning outcomes, as already discussed (Exhibit S19). Introducing and wrapping up subunits reduced the cognitive load for the live version as well, and ended up improving the teaching experience.

Moreover, each of the ten units of the online version is described by 1-2 paragraphs of text, which also explains the relationships between the main elements of the unit and related unit material, i.e. PowerPoint presentations, case studies and solved problems (Exhibit S5b).

Although most of the above changes were made for the convenience of the user, only in retrospect it became apparent to the instructor that they make sense from a cognitive view point as well. For example, meaningful titles are in agreement with the knowledge organization principle No 2 and distilling each course unit into its main messages provides an example of expert understanding (3-mastery principle).

\subsection{Pedagogical changes: applying research-based good practices}

Methodology-driven changes: As already mentioned, the major aim that drove course modifications was to make more transparent to students the way the course was designed (5-communication principle). This was done in a variety of ways:

- Course-level general learning objectives were supplemented with detailed learning outcomes for each course unit, as already mentioned (Exhibit S19). The live version of the course also highlights the relationship of the detailed learning outcomes to assignments and the term project, as in the example given in Table 4 (4motivation and 5-communication principles).

- Contents were reordered to make clearer to students the necessity of certain course units, thus rendering unnecessary the approach of: "you will see later the useful- 
ness of what I teach you now" (2-knowledge organization principle). For example, the fundamentals part of the course starts with a qualitative introduction on pollutant spreading in water (Unit 3: Exhibit S7), in order to stress the important role of groundwater velocity in Unit 7 on contaminant transport and, thus, motivates Unit 4 on groundwater flow.

- Qualitative description of phenomena precedes their quantitative-mathematical formulation. This also helped with revisiting topics and, thus, reinforcing key concepts (2-knowledge organization and 3-mastery principles). The qualitativequantitative sequence is implemented at two critical junctures of the course. As already alluded, the mechanisms of contaminant transport in water (advection, diffusion, mechanical dispersion) are introduced at the beginning of the course qualitatively, with the help of videos, analogies and simple experiments, before equations are introduced in Unit 7 on contaminant transport (Exhibit S7). Likewise, after completing Unit 6 on mass transfer and sorption, the manifestation of sorption as contaminant retardation is introduced with an analogy to an in-class "transport experiment". The experiment involves chocolates that move through classroom tables with specific rules towards the back of the classroom and demonstrates how "sorption" affects the mobility of chocolates passed on from table to table [5]. The concept of sorption manifested as retardation is further reinforced qualitatively with the results from the first solute transport experiment conducted at Borden [18] (Exhibit S11), before introducing the retardation factor that appears in the contaminant transport equation, which is discussed in Unit 7.

- The importance of key topics is stressed by visiting them often: key concepts are introduced during the first half of the course and are later reinforced several times in different applications (2-knowledge organization principle). Such key skills are estimating hydraulic gradient from the potentiometric map (i.e. hydraulic head map) of a real site and, with this information, calculating seepage velocity. Students do this in a homework assignment in the unit on groundwater flow (Exhibit S14), they repeat it when they need the advection velocity as input to the solution of the contaminant transport equation, and they have one more opportunity to practice in the unit on remediation technologies, in problems where they calculate the required width of a permeable reactive barrier (Exhibit S16).

A second systematic change was to supplement every lecture with multiple choice quiz-type questions in order to trigger recall (1-prior knowledge principle) and also, for the live course version, as an opportunity to provide feedback at the group level (5-communication principle). Students are told that the intent of the questions is diagnostic and not evaluative. Most questions require that the students think critically of course content (e.g. Do you agree with the statement "In general, we worry less about naturally-occurring substances in soil and groundwater compared with man-made chemicals?"). A few are meant to uncover or prevent misunderstandings, e.g. the question shown in Figure 2 about calculating hydraulic gradient between two points using distance (L1 or L2) or flow path length (L3 - the correct answer) between the two points. All the quiz-type questions developed for the course are listed in Exhibit 
$\mathrm{S} 1$ and comments on class discussion for selected questions are included in Exhibit S20.

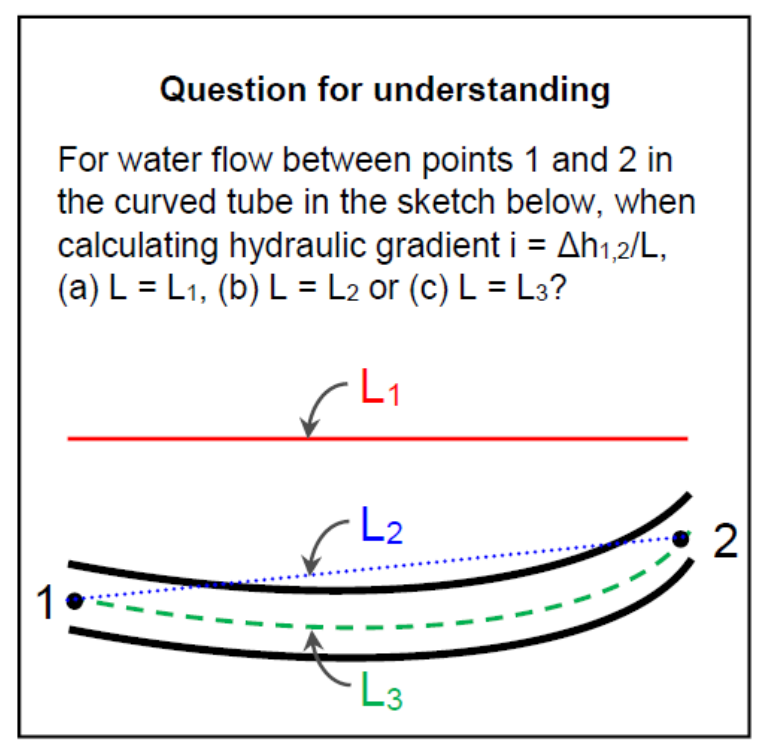

Fig. 2. Quiz-type question concerning alternatives for calculating hydraulic gradient between points 1 and 2. Quiz-type questions for Units 2-4 and 6-8 are provided in Exhibit S1 in the Supplement.

The difficulty in coming up with several meaningful quiz-type questions and phrasing them properly was a surprise to the first author. Part of the difficulty was due to initial inexperience with using multiple choice questions in exams, which was overcome to an extent after attending several massive open online courses (MOOCs) and getting ideas from the quiz-type questions used therein. For example, the experience of attending MOOCs revealed the usefulness of asking students to select from a list of statements all those with which they agree, without telling students how many may be true (could be only one, many or all). In order to avoid misunderstandings caused by the phrasing of questions, it was essential to run them by the second author, who has served for several years as graduate student teaching assistant of the course, for comments and modifications.

Given the difficulty of thinking quiz-type questions and ensuring their reliability, the first author would not have been diligent with devising them, had it not been for the paper by Karpicke and Grimaldi [12], which demonstrates convincingly the learning gains of students when being asked review- and understanding-type questions. Familiarity with the literature of education provided the necessary encouragement for not giving up a practice that reinforces learning.

Quiz questions also offer welcome opportunities to focus on concepts [19]. Too often, assessment in engineering courses is based primarily on problem solving and analysis. Rarely does assessment investigate the nature of concepts formed by stu- 
dents or how do students synthesize related mental constructs and concepts. Tellingly, Montfort et al. [20] found no significant improvements in conceptual understanding of key mechanics concepts among students in early and late years of an undergraduate civil and environmental engineering curriculum, as well as at the graduate level, despite improvements in their computational skills.

Content-related changes: Environmental Geotechnics is an applied field that draws fundamentals from physics, chemistry and introductory civil engineering courses. This section gives some pointers on mostly new educational material developed to address teaching needs specific to the subject matter.

The course is designed so that students get the necessary background to address the central issues at a contaminated site, with emphasis on case studies (4-motivation principle), as already mentioned. The subject matter is introduced with cases and nearly every course unit includes one case study. For example, Unit 2 on risk assessment presents the results from the risk assessment study performed in 1998 for the site Graces Quarters [21] and stresses that the carcinogenic and hazard indices would be different if the calculations were performed with the revised toxicity characteristics valid 15 years later (Exhibit S13).

The applied nature of the course facilitates connections with other civil engineering topics and courses (1-prior knowledge principle). Obvious connections are to classic geotechnical engineering topics (groundwater seepage due to consolidation, claycontaminant interactions). In one such instance, hydraulic conductivity is contrasted to the modulus of elasticity (Exhibit S2a), in order to make the point that hydraulic conductivity varies over many more orders of magnitude -specifically 11 orders of magnitude for soils-rocks- compared with most quantities common in civil engineering: e.g. modulus of elasticity varies by 2.5 orders of magnitude for soils-rocks, or 4.5 orders of magnitude if concrete is also taken into account. This comparison is doubly useful, because it shows that while concrete and clay can have comparable hydraulic conductivities, clay outperforms concrete when low permeability is desired for contaminant barriers, e.g. landfill liners. Connections are sought not only with subjects from previous years, but also cultivated early on, in anticipation of environmental courses involving biological phenomena in later years. To this end, the authors accepted the invitation of the instructor of a programming course taught in the $4^{\text {th }}$ semester to create educational material for a process described by a mathematical model programmable with MATLAB ${ }^{\circledR}$. They created a problem statement and a MATLAB ${ }^{\circledR}$ code that link the time needed to remediate a site contaminated by a chlorinated compound to the size of the community of the microorganisms mediating reduction of the compound to a less toxic byproduct (Exhibit $\mathrm{S} 2 \mathrm{~b}$ ).

Because tasks that involve complex phenomena can be challenging for students, as already mentioned in Section 2.3, it helps to support some aspects of the complex task (3-mastery principle). One such example is the unpacking of contaminant transport by demonstrating with targeted graphics the effect of each one of the contributing mechanisms (sorption, dispersion, degradation), as already mentioned in Section 2.3 and shown in Figure 1 (additional material is provided in Exhibit S9).

Lastly, the ongoing effort to identify problem areas of inaccurate understanding continued (1-prior knowledge principle), by crafting suitable qualitative questions, as 
described for the concept of soil structure in [4], and by monitoring of students' work for possible cues. Knowledge of the literature on common misconceptions

- Helps instructors not miss such cues and better understand the origin of inaccurate conceptions

- Gives an idea of their pervasiveness

- May offer guidance on how to address them in instruction.

Misconceptions (referred to also as "misunderstandings" [22]) are incorrect or naïve understandings of concepts or phenomena, often resistant to change through instruction [23].

For example, one misconception was identified serendipitously during the lecture break, in a discussion on a comment by a student. The discussion revealed that the student was envisioning for solute transport "solid" molecules of a contaminant in water (e.g. chromium, which is solid in its natural state). In the mind of the student, the contaminant, although in solution, had preserved its solid properties and was travelling like tiny beads suspended in water. This misconception is discussed in the paper "Is an atom of copper malleable?" [13], which concerns the, apparently common, fundamental misconception of extending properties of matter to the molecular and atomic level, e.g. believing that each atom or molecule of a solid substance is also solid.

Knowledge of the pervasiveness of this misconception helped in two ways. First, in identifying other instances of it in students' work. For example, in the answer to a conceptual question asking students to describe drying of clothes indoors vs outdoors using analogies from environmental geotechnics, one student wrote: "The drying of clothes primarily consists of liquid water molecules turning to gaseous water molecules". Second, the knowledge of the pervasiveness of the misconception helped in deciding to attempt to address it in class: knowing that deeply held misconceptions often persist despite direct instructional interventions [8], analogies related to the coffee culture of Greece were used hoping for increased retention (Exhibit S3). A slide clarifying that solid-liquid-gaseous states are emerging properties of assemblages of the same molecules is accompanied by a picture of instant coffee (the ubiquitous "Nescafé" of Greece), which visibly loses its solid state when mixed with water. Hence, Nescafé is recommended as a model for an aqueous solution. Nescafé is contrasted with Greek (or Arabic) coffee, which, with coffee grounds settling to the bottom, is a better model for transport of particles in suspension rather than solute transport.

Systematically addressing misconceptions is an undertaking that requires collaboration within the domain. The problematic topics mentioned in this section by no means exhaust the issue of identifying and remedying misconceptions in the fields of geotechnical and geoenvironmental engineering.

\subsection{Comments on course redesign}

At the end of it all, the instructor may ask "what was achieved with these course modifications?" Or, more generally, "how do instructors know that when they make 
changes in their courses, the changes result in learning improvements?" The answer is "they don't". If instructors give to students questionnaires asking them if they liked the changes, this is the exact information they will get. The literature shows that student self-assessment does not correlate with actual performance [24], [8]. What is more, self-assessment of students has been shown to be inaccurate when it concerns questions about what helped them learn [25].

But perhaps the question above is half the story. It is probable that when instructors introduce new educational material and activities in their courses, students appreciate the instructor's extra effort and give positive comments in questionnaires, especially when the instructor has tried something that alters the pace of a lecture-based course. Likewise, when instructors put more effort in their courses, it is reasonable to expect that their students benefit rather than lose.

The other half of the story is that when instructors follow evidence-based practices to develop educational materials and share them with colleagues, the teaching community becomes richer because it has more teaching tools and, hence, even more students can benefit. If these educational materials employ strategies supported by more than one learning principles, it is possible to result in higher learning gains for students.

Some instructional interventions intuitively appealing to instructors to keep students engaged, can also improve learning. Clickers, a hand-held device that allows the instructor to ask in-class questions and receive instant responses [26], are ideal for the quiz-type questions discussed herein. The use of clickers not only engages students but in combination with suitable questions also activates prior learning within the course.

\section{Conclusion}

At a high level, this paper gives a partial answer to the question "If I am familiar with the education literature what can I do better in my course?" through examples of implementing evidence-based teaching practices. At the same time, it helps instructors see that experience has led them to adopt practices compatible with results of research on learning. The teaching practices presented herein aimed to render course design decisions more transparent and make up for the lack of physical presence of the instructor in the online version of the course, while taking into account good practices stemming from research-based learning principles. The paper codified sequences of "learning principles $\rightarrow$ goals $\rightarrow$ strategies" from the literature on education, proposed domain-general implementations of these strategies, and gave example applications in an engineering course. These examples include, among others:

- Stating the essential questions that motivate study of the course subject

- Arranging course content in smaller, more manageable by the learner, stand-alone subunits

- Stating detailed learning outcomes for the main units of the course

- Creating diagnostic quiz-type questions that activate learning

- Including more real-world problems 
- Enunciating the gist of each unit (what are the main points? what is the take away message?) and of the entire course when the essential questions are answered at the course's completion.

The combination of "essential questions - learning outcomes - quiz-type questions" can provide a powerful complement to traditional teaching materials typically arranged in textbooks as "main chapters corresponding to key topics - theory behind key topics - homework problems involving the key topics". The paper stressed the challenges of enunciating the essential questions within a domain and devising quiztype questions. In so doing, it highlighted the necessity for the scientific community of a discipline to contribute to the production of communal teaching resources for the discipline, in the same way it contributes to the production of communal research resources.

The process followed in course redesign points to two major realizations. The first realization is related to the fact that, despite calls for accountability in education and the creation of open courses, instruction remains to a large extent a private issue between professor and students. Transparency in instructional decisions holds the promise to be a major driving force for change. Research findings on learning offer the conceptual framework and the means to make instruction public, like research is, and take it to a peer-review level.

The second realization concerns the essential questions and corresponding big ideas, which are part of the tacit knowledge of experts. Expert performance is characterized in the literature as unconscious competence: experts do not need to verbalize the organizational structure of their knowledge. This aspect of expertise, as already noted, does not help with teaching. Enunciating essential questions and the corresponding big ideas requires the input of domain experts who will likely need some examples and guidance to follow, in order to put in words what they take for granted. What is more, for a specialized topic, big ideas are of interest to relatively few. This scarcity is reflected in the literature on instruction and cognition, which mostly deals with comparing novice-expert understandings of basic topics taught to wide audiences, e.g. Newton's law. This realization leads to the identification of the research need to record how experts understand key domain concepts. Who will address this need? Mainly the instructor-expert has an incentive to do it and only the instructor-expert can (not just any instructor). Even better, a community of experts. Thus, instruction offers incentives for mapping the "knowledge bearing frames" experts have created each in their own domain, an undertaking that holds promise to help refocus research as well.

\section{Acknowledgement}

The participation of Kyriakos Kandris, then a PhD Candidate at the National Technical University of Athens, in the preparation of the academic open course Environmental Geotechnics was supported through the Operational Program "Education and Lifelong Learning 2007-2013" co-financed by the European Union (European Social Fund ESF) and Greek national funds. 


\section{$6 \quad$ References}

[1] National Technical University of Athens (2019a). School of Civil Engineering, Courses, 9th Semester, Environmental Geotechnics: http://www.civil.ntua.gr/courses/119/ (accessed October 9, 2019).

[2] National Technical University of Athens (2019b). Academic Open Courses, Course: Environmental Geotechnics (in Greek): https://ocw.aoc.ntua.gr/courses/CIVIL115/ (accessed October 9, 2019).

[3] Pantazidou, M. and Steif, P., Modeling instruction in an environmental geotechnics course, GeoCongress 2008, March 9-12 2008, New Orleans, USA, ASCE Geotechnical Special Publication No. 178, pp. 797-804. https://doi.org/10.1061/40971(310)99

[4] Pantazidou, M., Student understanding of the concept of soil structure guides instructional interventions, 17th Int. Conf. on Soil Mechanics and Geotechnical Engineering, October 59 2009, Alexandria, Egypt, pp. 2758-2761.

[5] Pantazidou, M. (2010). The Scholarship of Teaching: A case in Environmental Geotechnics, In: Inquiries into European Higher Education in Civil Engineering, 9th Vol., Erasmus Thematic Network: European University Civil Engineering Education and Training (EUCEET), I. Manoliu (Ed.), pp. 125-152.

[6] Borrego, M., Streveler, R.A., Miller, R.L. and Smith, K.A. (2008). A new paradigm for a new field: communication representations of engineering education research. J. of Engineering Education, 97: 2: 147-162. https://doi.org/10.1002/j.2168-9830.2008.tb00964.x

[7] Jamieson, L.H. and Lohmann, J.R. (2012). Innovation with impact: Creating a culture for scholarly and systematic innovation in engineering education, American Society for Engineering Education, Washington, DC, USA, p. 77, https://www.asee.org/memberresources/reports/Innovation-with-Impact (accessed October 9, 2019).

[8] Ambrose, S.A., Bridges, M.W., DiPietro, M., Lovett, M.C. and Norman, M.K. (2010). How learning works: 7 researched-based principles for smart teaching, Jossey-Bass, San Francisco, CA, USA, $301 \mathrm{p}$.

[9] Sadler, P.M, Sonnert, G., Coyle, H.P., Cook-Smith, N. and Miller, J.L. (2013). The influence of teachers' knowledge on student learning in middle school physical science classrooms, American Educational Research Journal, 50: 5: 1020-1049. https://doi.org/10.3102/0002831213477680

[10] Wiggins, G. and McTighe, J. (2005). Understanding by design, Expanded 2nd Edition, Association for Supervision and Curriculum Development, Alexandria, VA, USA, p. 370.

[11] Pantazidou, M. and Kandris, K. Online Supplement http://users.ntua.Gr/mpanta/Teaching_EN/EnvironmentalGeotechnics/Supplement_P_K_2 019/ (accessed October 9, 2019).

[12] Karpicke, J.D. and Grimaldi, P.J. (2012). Retrieval-based learning: A perspective for enhancing meaningful learning, Educational Psychology Review, 24: 3: 401-418. https://doi.org/10.1007/s10648-012-9202-2

[13] Ben-Zvi, R., Bat-Sheva, E. and Silberstein, J. (1986). Is an atom of copper malleable? J. of Chemical Education, 63: 1: 64-66. https://doi.org/10.1021/ed063p64

[14] Glaser, R. and Chi, M.T.H. (1988). An overview, In: M.T.H. Chi, R. Glaser and M.J. Farr (Eds.), The nature of expertise, xv-xxviii, Lawrence Erlbaum Associates, Hillsdale, NJ, USA.

[15] Lawton, D., Vye, N., Bransford, J., Sanders, E., Richey, R., French, D. and Stephens, R. (2012). Online learning based on essential concepts and formative assessment, J. of Engineering Education, 101: 2: 244-287. https://doi.org/10.1002/j.2168-9830.2012.tb00050.x 
[16] Daly, S.R., Mosyjowski, E.A. and Seifert, C.M. (2014). Teaching creativity in engineering courses, J. of Engineering Education, 103: 3: 417-449. https://doi.org/10.1002/jee.20048

[17] Valocchi, A.J., Werth, C.J., Decker, J.J., Hammond, G., Zhou, P. and Hafiz, M. (2014). Interactive Models for Groundwater Flow and Solute Transport, http://hydrolab.illinois.edu/gw_applets/(accessed October 18, 2019).

[18] Roberts, P.V., Goltz, M.N. and Mackay, D.M. (1986). A natural gradient experiment on solute transport in a sand aquifer 3. Retardation estimates and mass balances of organic solutes, Water Resources Research, 22: 13: 2047-2058. https://doi.org/10.1029/ WR022i013p02047

[19] Fellin, W. and Medicus, G. (2015). Multiple-choice tests: More than a time saver for teachers, Int. J. of Engineering Pedagogy, 5: 3: 15-24. https://doi.org/10.3991/ijep.v5i3.4376

[20] Montfort, D., Brown, S. and Pollock, D. (2009). An investigation of students' conceptual understanding in related sophomore to graduate-level engineering and mechanics courses, J. of Engineering Education, 98: 1: 111-129. https://doi.org/10.1002/j.21689830.2009.tb01011.x

[21] US EPA (2004). Superfund Record of Decision: Aberdeen Proving Ground (Edgewood Area), EPA ID: MD2210020036, OU 21, EPA/ROD/R03-04/607.

[22] Goris, T.V. (2016). Common misunderstandings of electricity: Analysis of interview responses of electrical engineering technology students, Int. J. of Engineering Pedagogy, 6: 1: 4-10. https://doi.org/10.3991/ijep.v6i1.5146

[23] Streveler, R.A., Brown, S., Herman, G.L. and Montfort, D. (2014). Conceptual change and misconceptions in Engineering Education, pp. 83-101, Chapter 5 in: Cambridge Handbook of Engineering Education Research, Johri, A. and Olds, B.M. (Editors), Cambridge University Press, New York, NY, USA https://doi.org/10.1017/CBO9781139013451.008

[24] Kruger, J. and Dunning, D. (1999). Unskilled and unaware of it: How difficulties in recognizing one's own incompetence lead to inflated self-assessments, J. of Personality and Social Psychology, 77:6:1121-1134 https://doi.org/10.1037/0022-3514.77.6.1121

[25] Yadav, A., Shaver, G.M. and Meckl, P. (2010). Lessons learned: Implementing the case teaching method in a mechanical engineering course, J. of Engineering Education, 99: 1: 55-69. https://doi.org/10.1002/j.2168-9830.2010.tb01042.x

[26] Chen, J.C., Whittinghill D.C. and Kadlowec J.A. (2010). Classes that click: Fast, rich feedback to enhance student learning and satisfaction, J. of Engineering Education, 99: 2: 159-168. https://doi.org/10.1002/j.2168-9830.2010.tb01052.x

\section{$7 \quad$ Authors}

Marina Pantazidou is an associate professor at the National Technical University of Athens, School of Civil Engineering, Department of Geotechnical Engineering, Iroon Polytechniou 9, Zografou 15780, Greece. Apart from university appointments in the US and Greece, her professional experience also includes work in hazardous waste consulting. Her research topics are drawn from environmental geotechnics and engineering education. Email: mpanta@central.ntua.gr

Kyriakos Kandris is a research engineer currently employed at Emvis Consultant Engineers SA (Paparrigopoulou 21, Ag. Paraskevi 153 43, Greece). His research focus lies mostly on solving inverse problems of fate and transport models in surface 
Paper-Examples of Applying Research-Based Learning Principles to The Redesign ...

and ground water applications. He is also a journal peer reviewer for the Bulletin of Environmental Toxicology and Contamination and the Bioremediation Journal.

Article submitted 2019-07-08. Resubmitted 2019-10-18. Final acceptance 2019-10-19. Final version published as submitted by the authors. 